\title{
ARTICLE
}

Cite this: DOI: $10.1039 / x 0 x x 00000 x$

Received 00th January 2012,

Accepted 00th January 2012

DOI: $10.1039 / \times 0 x \times 00000 x$

www.rsc.org/

\section{Producing hierarchical porous carbon monoliths from hydrometallurgical recycling of spent lead acid battery for application in lithium ion batteries}

\author{
XiongHe ${ }^{\mathrm{a}}$,Xiaoyu Peng ${ }^{\mathrm{a}}$, Yuxuan Zhu ${ }^{\mathrm{b}}$, \\ ChaoLai $^{\mathrm{b} *}$,Caterina Ducati ${ }^{\mathrm{a}}$, R.Vasant Kumar ${ }^{\mathrm{a} *}$
}

In this paper, an environmentally clean process to recycle the paste from a spent lead acid battery (LAB) is further developed in order to produce a porous carbon anode material for a lithium ion battery (LIB) which is currently in increasing focus as the solution for future energy storage and distribution network. Using lead citrate from hydrometallurgical leaching of lead paste as a precursor, electrochemically active carbon materials were produced as a new product with hierarchical open sponge-like porosity. It was found that anode materials made from porous carbon by pyrolysing lead citrate at $500^{\circ} \mathrm{C}$, with high micropore $(<2 \mathrm{~nm})$ volume $\left(0.1906 \mathrm{~cm}^{3} / \mathrm{g}\right)$ and BET surface area $\left(138 \mathrm{~m}^{2} / \mathrm{g}\right)$, showed remarkable reversible capacity values beyond intercalation at both low and high current densities. In particular, at the high current density of $5000 \mathrm{~mA} \mathrm{~g}-1$ (13.4C, according to the theoretical capacity of $372 \mathrm{mAh} \mathrm{g-1),} \mathrm{a} \mathrm{high} \mathrm{discharge} \mathrm{capacity} \mathrm{of} 217 \mathrm{mAh}$ g-1 was maintained even after 200 cycles, much superior in comparison with other carbon materials.

most of the spent LABs are recycled by using pyrometallurgical process, which are associated with environmental issues arising from lead dust and sulphur dioxide emission ${ }^{2}$. Therefore, hydro-metallurgical processes are increasingly studied to avoid the high temperature dependent pollution ${ }^{3-5}$. The new processes can help to reduce dust and acid pollution by the removal of sulphur by leaching and avoidance of lead fuming from the low operating temperature. Citrate chelation has been proved to be effective for desulphurization of spent lead acid battery paste, while simultaneously fixing lead in lead citrate crystals ${ }^{6}$. Lead citrate crystal is a versatile raw material from the new process as it can be readily combusted in air at relatively low temperatures (below lead fuming temperatures) to produce leady oxides for making new batteries and/or pyrolysed in absence of oxygen to produce metallic lead and highly active carbon for new applications. The main concern is 
the currently relatively high price of sodium citrate reagent which makes the operating costs less economically friendly for recycling $\mathrm{LABs}^{7}$. Therefore, the process should be tailored to be economically more viable, by producing a high value electrochemically active carbon from a proportion of the lead citrate.

Highly active carbon materials have been widely used in energy-related applications (supercapacitor, lithium ion battery (LIB), lithium sulphur battery, gas storage $)^{8,9}$.Especially in LIBs, carbon materials in many forms such as graphite/graphitized carbon, CNTs, graphene and amorphous carbon has been proved to be the primary choice for the anode material $^{10}$ due to its useful chemical and physical properties. Carbon materials have been widely used in battery industry. As anode materials for LIBs, graphite, one-dimensional (1D), twodimensional (2D) and porous carbon have been explored. Graphite has a limited theoretical capacity of $372 \mathrm{mAh} \mathrm{g}^{-1}$ by forming stoichiometry $\mathrm{LiC}_{6}$. Nanostructured carbon materials, such as carbon nanotubes (CNTs), including single wall carbon nanotube (SWCNT) and multiwall carbon nanotube (MWCNT), carbon nanofibres (CNFs), graphene and porous carbon with various pore sizes can improve electrochemical performance due to their special structures and morphologies. 1D nanostructured carbons obtain high Coulombic efficiency and good cycling stability, but poor rate performance and low volumetric energy density. Graphene carbons have good rate capability but low initial Coulombic efficiency and large irreversible capacity. Porous nanostructured carbons which combine both the advantages of nano and micro are more attractive. ${ }^{11}$ Similar to LIBs, Na-ion batteries (NIBs) can also take advantages of carbon materials. ${ }^{12}$ Acting as part of the cathode materials of lithium sulfur batteries (LSBs), nanostructured carbon materials can also contributes to future energy storage solutions. ${ }^{13}$ Nanostructured porous carbon materials which have outstanding physical and chemical properties are of great importance in the battery industry.Among all the carbonaceous materials, 3D amorphous porous carbon with different range of pore size meets the requirements for LIB anode materials best by providing robust mechanical strength and high reversible specific capacity. ${ }^{11}$ Porous carbon can be classified as microporous $(<2 \mathrm{~nm})$, mesoporous $(2-50 \mathrm{~nm})$ and macroporous $(>50 \mathrm{~nm})$ based on its average pore size. Many methods have been developed to synthesize porous carbon obtaining different pore size and pore size distribution range ${ }^{9,14}$. These include synthesis of uniform porous carbon by using: Zeolite $\mathrm{Y}$ template, ${ }^{15,16}$ silica template $^{17}$ and anodic aluminum oxide templates, ${ }^{18}$ and hierarchical porous carbon from various precursors, such as polymers, copolymers and biomass. ${ }^{9}$ Some researchers have tried to utilize waste materials, food, agriculture waste and insects as the source of carbon. ${ }^{19}$ Developing low-cost and environmental-friendly process of synthesizing functional carbon with excellent properties is increasingly popular.

In this work we demonstrate the synthesis of hierarchical porous carbon materials as a co-product from a novel environmental-friendly hydrometallurgical LAB recycling process. We have examined the properties of the derived carbon for LIB applications. Lead sulphate, the main component of paste from spent LABs, was used as starting lead-containing raw material, According to previous study, ${ }^{20}$ spent LAB paste is a complex mixture of lead sulphate, lead oxides and metallic lead. The lead sulphate in spent LAB paste is identical in structure to pure lead sulphate. The structure of the lead citrate produced from spent LAB paste and pure chemicals is also the same. So we reasonably choose pure lead sulphate here to simulate spent LAB paste. By leaching lead sulphate with sodium citrate/citric acid buffer solution at room temperature, desulphurization was completed by transferring all lead into lead citrate precursors which were then converted to a leadcarbon composite after low temperature calcination (pyrolysis) at $500^{\circ} \mathrm{C}$ in $\mathrm{Ar}$ or $\mathrm{N}_{2}$. Lead was recovered from the lead-carbon composite with nitric acid to transfer lead into an aqueous solution from which lead can be recovered by electrowinning. Thus from the composite, porous carbon is recovered as the remaining phase as an important co-product of this process. Hierarchical porous carbon was then characterized and demonstrated to be a suitable host for lithium as an anode material for a LIB.

\section{Experimental}

\section{Materials and Methods}

The novel LAB recycling process using leaching/desulphurization with citric acid system and electrowinning is schematically described in Fig. 1, with the additional incorporation of pyrolysis to synthesize hierarchical porous carbon for LIB anode materials. The green dash line arrows indicate experiments proposed but not included in this paper. Those investigated and reported in this paper are desulphurization process, thermal process, porous carbon isolation process and LIB preparation and testing. Since, lead sulphate is the major component in a spent LAB paste, and also the most difficult component to recover or transform, ${ }^{6}$ pure lead sulphate, was used to simulate spent LAB paste.

\section{Preparation of lead citrate precursors}

Preparation of lead citrate precursors, also the desulphurization of lead sulphate (trace metals basis, 99.995\%), was conducted by following a modified previous reported method. ${ }^{5} 10 \mathrm{~g}$ of lead sulphate powder was added to $50 \mathrm{~mL}$ citric acid(citric acid monohydrate, ACS reagent, $\geq 99.0 \%$ ) and sodium citrate(sodium citrate tribasic dehydrate, ACS reagent, $\geq 99.0 \%$ ) solution ( $\mathrm{pH} 5.4$, $1.98 \mathrm{M})$. Citric acid acts as the $\mathrm{pH}$ buffer to obtain the optimal lead recycling efficiency. Leaching experiments were then conducted in a $250 \mathrm{~mL}$ glass beaker with constant magnetic stirring at $30^{\circ} \mathrm{C}$ for 6 hours (although 2 hours has been proved long enough for complete desulphurization). After leaching, the precipitated solids were filtered, washed with distilled water and dried at $90^{\circ} \mathrm{C}$ for 12 hours to obtain lead citrate crystals.

\section{Preparation of hierarchical porous carbon material}

The lead citrate crystalline powder was then pyrolyzedin absence of air at selected temperatures of 350,500 and $800^{\circ} \mathrm{C}$ in flowing argon (at $50 \mathrm{~mL} / \mathrm{min}$ ) for 1 hour. The resulting product which was shown to be a lead-carbon composite was carefully collected then reacted with $1 \mathrm{M}$ nitric acid solution for 6 hours at $40^{\circ} \mathrm{C}$ to isolate porous carbon while dissolving lead. The remaining black paste was then washed with distilled water and centrifuged to obtain a black mass found to be carbon with a hierarchical porous structure (Fig.2). The as 
prepared hierarchical porous carbon, after drying in an oven was then tested as anode host material for a LIB.

\section{Preparation of and electrochemical testing of the anodes}

The working electrodes were prepared by compressing a mixture of the active materials, acetylene black, and binder (polytetrafluoroethylene, PTFE) in a weight ratio of 70:20:10. The carbon anodes were cut into wafer with diameter of $8 \mathrm{~mm}$ and the loading is $3.6-4 \mathrm{mg} \mathrm{cm}^{-2}$. Lithium metal was used as the counter and the reference electrode. The electrolyte was $\operatorname{LiPF}_{6}(1 \mathrm{M})$ dissolved in a mixture of ethylene carbonate (EC), ethyl methyl carbonate (EMC) and dimethyl carbonate (DMC) with a volume ratio of $1: 1: 1^{21,22}$. Pouch type half-cells were used to test the electrochemical properties of the active materials. LAND-CT2001A galvanostatic test equipment was employed to measure electrochemical capacity and cycle life at room temperature of the working electrodes at selected values of current densities of 100, 1000 and $5000 \mathrm{~mA} \mathrm{g-1.} \mathrm{The} \mathrm{cut-}$ off potentials for charge and discharge were set at 3.0 and $0.05 \mathrm{~V}$ (vs. $\mathrm{Li}+/ \mathrm{Li}$ ), respectively.

\section{Characterizations}

The phase composition of the lead citrate crystalline powder and porous carbon were investigated by using Bruker D8-advanced powder X-ray diffractometer with $\mathrm{Cu} K \alpha$ radiation $(40 \mathrm{kV}$, $40 \mathrm{~mA}$ ).Microstructure of samples was observed with FEI Nova NanoSEM and FEI Tecnai F20 FEGTEM. Nitrogen adsorptiondesorption isotherms were measured on a Micrometrics ASAP 2020 instrument. The Brunauer-Emmett-Teller (BET) surface area was estimated over a relative pressure $\left(\mathrm{P} / \mathrm{P}_{0}\right)$ range of $0.01-0.20$. The pore size distribution and pore volume was estimated from the analysis of the adsorption branches of the isothermal using the Barrett-Joyner-Halenda (BJH) method. The $t_{\mathrm{HJ}}$-plot micropore volume is calculated using Harkins and Jura method. Raman data were obtained on a Dilor XY-800 spectrometer, using $514 \mathrm{~nm}$ wavelength laser. Thermal gravimetric analysis (TGA) was conducted on a TA Instruments Q2000 thermal analyser in argon and air with a heating rate of $10{ }^{\circ} \mathrm{C} \mathrm{min}^{-1}$.

\section{Results and discussion \\ Synthesis of lead citrate precursors}

In the desulphurization process, lead sulphate reacts with free citrate ions in the solution by forming $\mathrm{Pb}_{3}\left(\mathrm{C}_{6} \mathrm{H}_{5} \mathrm{O}_{7}\right)_{2} \cdot 3 \mathrm{H}_{2} \mathrm{O}$ as white precipitate. The reaction between $\mathrm{PbSO}_{4}$ and $\mathrm{Na}_{3} \mathrm{C}_{5} \mathrm{H}_{5} \mathrm{O}_{7} \cdot 2 \mathrm{H}_{2} \mathrm{O}$ followed the reaction (1).,23

$3 \mathrm{PbSO}_{4}+2 \mathrm{Na}_{3}\left(\mathrm{C}_{6} \mathrm{H}_{5} \mathrm{O}_{7}\right) \cdot 2 \mathrm{H}_{2} \mathrm{O} \rightarrow \mathrm{Pb}_{3}\left(\mathrm{C}_{6} \mathrm{H}_{5} \mathrm{O}_{7}\right)_{2} \cdot \mathrm{xH}_{2} \mathrm{O}$

$+3 \mathrm{Na}_{2} \mathrm{SO}_{4}+(4-\mathrm{x}) \mathrm{H}_{2} \mathrm{O}$

According to previous reported results ${ }^{5,6}$, complete desulphurization of lead sulphate can be completed within 2 hours at room temperature. Here the leaching time was extended to 6 hours, and leaching temperature was kept at $30^{\circ} \mathrm{C}$, in order to ensure complete absence of any unreacted lead sulphate in the lead citrate precursor.

SEM figure (Fig.3a)of the lead citrate displayed a thin plate like structure (less than $5 \mu \mathrm{m}$ in length). Although the lead citrate precursors seemed well crystalized in the SEM image, the XRD spectra (Fig.3b) indicated relatively poorly crystallized pattern with only one sharp peak at $2 \theta=8.95^{\circ}$ and two broad peaks at around
$2 \theta=27^{\circ}$ and $42^{\circ}$.The one sharp peak can be allocated to $\mathrm{Pb}_{3}\left(\mathrm{C}_{6} \mathrm{H}_{5} \mathrm{O}_{7}\right)_{2} \cdot 3 \mathrm{H}_{2} \mathrm{O}$ which is known to have one strong peak around that range ${ }^{7}$. No lead sulphate peaks were observed.

\section{Thermal decomposition of lead citrate precursors}

TGA/DSC curves of the lead citrate precursor are shown in Fig.4.There are three stages of weight loss during the decomposition in absence of air $\left(\mathrm{N}_{2}\right.$ was used). The first weight loss stage started from about $170^{\circ} \mathrm{C}$ can be assigned to dehydration and loss of water of crystallization. The broad DSC peaks at around $200-270^{\circ} \mathrm{C}$ indicate complex decomposition reactions. The next sharp DSC peak at around $350^{\circ} \mathrm{C}$ and the corresponding drastic mass loss (14.15wt \%) can also be ascribed to lead citrate decomposition. No further mass loss stage after the completion of the endothermic process at around $350^{\circ} \mathrm{C}$ is observed, which is taken as an indication of termination of lead citrate decomposition. The total mass loss at $500^{\circ} \mathrm{C}$ is $32.9 \mathrm{wt} \%$, which corresponds well with the theoretical mass loss of $33.6 \mathrm{wt} \%^{24}$. The mass loss curve then remains stable until $800^{\circ} \mathrm{C}$ with only a gradually slowly decrease arising most probably from evaporation of lead. The total mass loss at $800^{\circ} \mathrm{C}$ is $34.8 \mathrm{wt} \%$. Another significant mass loss stage starts from around $850^{\circ} \mathrm{C}$ which is considered as arising from increased lead evaporation. In order to select the optimal calcination temperature, two further thermal analyses have also been conducted with heating temperatures up to $350^{\circ} \mathrm{C}$ and $500^{\circ} \mathrm{C}$.Based on the thermal analysis results, three different calcination temperatures $\left(350,500\right.$ and $\left.800^{\circ} \mathrm{C}\right)$ were chosen to produce porous carbon materials.

According to Brown's research report ${ }^{24}$, pyrophoric lead and carbon are the final products of lead citrate decomposition in inert gas atmosphere with a weight loss of around $33.6 \mathrm{wt} \%$. The proposed reaction was described as:

$\mathrm{Pb}_{3}\left(\mathrm{C}_{6} \mathrm{H}_{5} \mathrm{O}_{7}\right)_{2} \cdot 3 \mathrm{H}_{2} \mathrm{O}(\mathrm{s}) \rightarrow[3 \mathrm{~Pb}+7.5 \mathrm{C}](\mathrm{s})+5 \mathrm{H}_{2} \mathrm{O}(\mathrm{g})+4.5 \mathrm{CO}_{2}(\mathrm{~g})(2)$

The most common thermal decomposition products are $\mathrm{Pb}$ (labeled with blue arrows) and $\mathrm{C}$, shown in Fig. $5 \mathrm{c}$ and the mixture also consists of some $\mathrm{PbO}$ (labeled with black arrow). The presence of lead oxides has mainly resulted from the oxidation of nano-sized pyrophoric lead particles. While the lead particles were oxidized to lead oxides, the carbon monolith and its surface area would be expected to remain unchanged. ${ }^{25-27}$ According to the TGA analysis, it is reasonable to assume that the decomposition process is following the above equation. The loss of carbon in the following collecting process can be neglected. Then the carbon yield of the lead citrate decomposition process is $7.9 \%$. The SEM images are shown in Fig.5a\&b. As displayed in the SEM images, the product consisted of numerous isolated round lead particles with a wide size range distributed on the carbon matrix. The maximum particle size of lead metal is around $50 \mathrm{~nm}$. Some of the lead metal particles were partially adhered in carbon, some were attached on the surface of carbon and some were fully located inside carbon particles. The particle size of some of the lead particles is very small $(<50 \mathrm{~nm})$. According to Feitknecht's research, lead metal with surface area higher than $3 \mathrm{~m}^{2} / \mathrm{g}$ will have pyrophoric behavior. ${ }^{24}$ Then the as prepared lead particles will be expected to have pyrophoric behavior. 
To obtain as much as carbon as possible, the decomposition products should be transferred into next step as soon as possible from argon protected furnace preventing from exposure to air.Fig. $5 \mathrm{~d}$ shows the TEM image of lead carbon composite. The black particles in the image are lead. As indicated by the color differences inside the particles, the round lead spheres with above $20 \mathrm{~nm}$ diameters are not uniform but more likely to be formed by agglomeration of smaller lead particles.

\section{Characterization of porous carbon}

Fig.6a shows the Raman spectra of carbon produced from lead citrate precursor at three different decomposition temperatures (350, 500 and $800^{\circ} \mathrm{C}$ ). Fundamental vibrations of $\mathrm{D}$ bands (the $\mathrm{A}_{1 \mathrm{~g}}$ symmetry mode, disorder) in the vicinity of $1320 \mathrm{~cm}^{-1}$ and $\mathrm{G}$ bands (the $E_{2 g}$ mode of the $\mathrm{sp}^{2}$ carbon atoms, graphite) in the vicinity of $1590 \mathrm{~cm}^{-1}$ were clearly observed for the obtained carbon materials. As the annealing temperature increases from $350^{\circ} \mathrm{C}$ to $800^{\circ} \mathrm{C}$, the intensity ratio of D-band and G-band, $\mathrm{I}(\mathrm{D}) / \mathrm{I}(\mathrm{G})$, increases from 0.70 to 1.19 , suggesting higher content of disorder carbon sheets. ${ }^{28-30}$ More disorder structure may offer more active sites for lithium-ion storage.Fig.6b shows the XRD patterns of the same carbon materials. The two broad peaks at around 2 theta $=23.5^{\circ}$ and $42.5^{\circ}$, which correspond to $\left(\begin{array}{lll}0 & 0 & 2\end{array}\right)$ and $\left(\begin{array}{lll}1 & 0 & 0\end{array}\right)$ reflections, denote disordered graphitic carbon. ${ }^{19,31}$ There is no other impurity peak, such as lead, indicating the complete removal of metal residues. This also can be further confirmed by the TGA curves of porous carbon in Fig. S1. As presented, the weight loss can reach to $100 \%$ before $500{ }^{\circ} \mathrm{C}$ in air.

SEM images of theporous carbon material, Fig.7a and Fig.7b, display a surface morphology characterized by craters with different diameters and depth. The diameter of the craters, which ranges from 2 to $50 \mathrm{~nm}$, matches well with the size of the lead metal showed in Fig.5a,b. The carbon bulk shows a curved surface, which results from the constraining force during the pyrolysis. $^{24}$ The HR-TEM images in Fig.7c,d,e show a hierarchical, open 3D-porous morphology which indicates the existence of varying size of pores inside the carbon matrix as well, which is evidently proved by the overlap of the pores. The whole carbon matrix looks more like a piece of micro-sized sponge. The pores located inside carbon matrix also have similar diameters as the surface craters, as indicated in Fig.7d. In accordance with XRD and Raman results, HR-TEM also reveals a disordered structure, Fig.7f.

Energy dispersive X-ray spectrometry (EDX) mapping analysis is also conducted to investigate the surface element state of porous carbon. As shown in Fig. S2, the overlapped element mapping indicates the homogeneous distribution of carbon and oxygen on the surface of the porous carbon. The EDS spectrum in Fig. S3 obtained from the same region of the sample confirms the presence of oxygen atoms. There are no lead peaks detected, in consistent with the results of TGA. To further illustrate the content of existing state of carbon and oxygen, XPS spectrums are given in Fig.8. XPS survey scan in Fig. 8a confirm the presence of carbon and oxygen atoms in the porous carbon, and there are no obvious difference for the carbon materials calcined at different temperature, except that the oxygen content increases from 13.52 atm $\%$ to 15.75 and 14.33 atm $\%$ as the annealing temperature increases from $350^{\circ} \mathrm{C}$ to $800^{\circ} \mathrm{C}$. Fig. $8 \mathrm{~b}$ is the the XPS core level spectra of $\mathrm{C} 1 \mathrm{~s}$ of the sample obtained at 500 ${ }^{\circ} \mathrm{C}$. The peaks centered at 284.4 and $284.9 \mathrm{eV}$ can be attributed the $\mathrm{C}=\mathrm{C} / \mathrm{C}-\mathrm{C}$ groups. ${ }^{32,33}$ The peaks centered at 285.8 and 286.9 $\mathrm{eV}$ are related to the $\mathrm{C}-\mathrm{O}$ epoxy and hydroxyl groups, while the peaks at 288.4 and $289.2 \mathrm{eV}$ are designated as $\mathrm{C}=\mathrm{O}$ carbonyl groups and $\mathrm{O}=\mathrm{C}-\mathrm{O}$ carboxyl groups. ${ }^{32}$ There are no obvious peaks of lead is detected (below 0.13 atm\%), in consistent with above characterizations. The formation of $\mathrm{C}-\mathrm{O}$ and $\mathrm{C}=\mathrm{O}$ groups is also can be further confirmed by the FTIR spectrum in Fig. S4.

The $\mathrm{N}_{2}$ sorption isotherms and the $\mathrm{BJH}$ pore size distribution of porous carbon produced at three different temperatures are shown in Fig.9.As shown in Fig.9a, all the isotherms exhibit a typical IV isotherm, with an obvious hysteresis loop, indicating the existence of mesoporous structure. ${ }^{19}$ Point B, labeled with a blue arrow, indicates the completion of monolayer coverage and the start of multilayer adsorption. ${ }^{34}$ These hysteresis loops can be categorized as $\mathrm{H} 4$ type, which indicates absence of large mesopores embedded in monolith with smaller pores. ${ }^{35}$ The presence of low pressure hysteresis, especially obvious in $500^{\circ} \mathrm{C}$ carbon, indicates the existence of micropores in the carbon materials. This may also indicate a non-rigid porous structure which results in the swelling of the absorbent. ${ }^{34}$ The steep fall of desorption branch at lower limit of hysteresis indicates the existence of disordered domains resulting from collapse of lamellar structure, which matches the SEM results (Fig.5a\&b). As shown in Fig. 9a, high temperature annealed carbon possess bigger hysteresis lop, which indicates the larger mesopore volume. At point $\mathrm{B}$ and final adsorption stage, high temperature carbon $\left(500^{\circ} \mathrm{C}\right.$ and $\left.800^{\circ} \mathrm{C}\right)$ absorbed more $\mathrm{N}_{2}$, which manifests larger outside surface area. The PSD (pore size distribution) pattern (Fig. $9 \mathrm{~b}$ ) and the quantitative results (Table. 1) provide further verification. As indicated by the more obvious low pressure hysteresis loop and higher BJH adsorption at smaller pore size $(2-5 \mathrm{~nm})$, porous carbon produced at $500^{\circ}$ Cgives a larger BET surface area of $138.5 \mathrm{~m}^{2} \mathrm{~g}^{-1}$, a larger micropore volume of $0.0248 \mathrm{~cm}^{3} \mathrm{~g}^{-1}$ and a smaller average pore size of $15.1 \mathrm{~nm}$. The decrease of micropore volume, concurrently the increase of mesopore volume, at $800^{\circ} \mathrm{Cin}$ comparison with $500^{\circ} \mathrm{Csamplesmay} \mathrm{result} \mathrm{from} \mathrm{the} \mathrm{coalescing}$ of lead metals at the smaller size.

\section{Battery test results}

Porous carbon has been widely used in many energy and environment related areas, such as in supercapacitors ${ }^{36}$, batteries $^{37,38}$, and hydrogen storage ${ }^{39}$. But in this paper, LIB batteries application, as one of the possible applications of this as-prepared porous carbon materials are considered. The electrochemical performance of the carbon material, prepared as a working electrode as described in the experimental section, was firstly tested in a half cell using lithium metal as the counter electrode. The initial discharge-charge curves at the 
current density of $100 \mathrm{~mA} \mathrm{~g}^{-1}$ are presented in Fig. 10a. As shown, all the samples display similar sloping discharge curves, which is a typical feature for carbon materials with a low degree of graphitization. ${ }^{40}$ The plateau between $0.5-0.9 \mathrm{~V}$ can be attributed to the formation of the solid electrolyte interphase (SEI) film arising from the decomposition of the electrolyte. The sample thermally treated at $350{ }^{\circ} \mathrm{C}$, shows a high discharge capacity of $620.9 \mathrm{mAh} \mathrm{g}^{-1}$ (per $\mathrm{g}$ of active materials), but a very low charge capacity of $137.5 \mathrm{mAh} \mathrm{g}^{-1}$, indicating that the activation process at this temperature is not sufficient for applications in Li-ion batteries. When the higher temperature was used, a significant increase of the initial capacity can be observed. The initial discharge-charge capacity is 1629.1 and $849.7 \mathrm{mAh} \mathrm{g}^{-1}$, respectively, for the samples treated at $500{ }^{\circ} \mathrm{C}$, while it is 1233.3 and $676.4 \mathrm{mAh} \mathrm{g}^{-1}$ for the sample treated at $800{ }^{\circ} \mathrm{C}$. The large irreversible capacity and low initial coulombic efficiency $\left(350{ }^{\circ} \mathrm{C}: 22.1 \% ; 500{ }^{\circ} \mathrm{C}: 52.1 \% ; 800\right.$ ${ }^{\circ} \mathrm{C}: 54.8 \%$ )mainly result from the formation of SEI layer and irreversible lithium insertion sites within the porous carbon material. ${ }^{26}$ Fig. $10 \mathrm{~b}$ shows the cycle curves of the samples obtained at different temperatures at the current density of 100 $\mathrm{mA} \mathrm{g}^{-1}$. As illustrated, the carbon materials obtained at $500{ }^{\circ} \mathrm{C}$ present the highest reversible capacity, and after 50 cycles, the discharge capacity can be retained at $669.0 \mathrm{mAh} \mathrm{g}^{-1}$, which is much higher than the theoretical capacity of graphite anodes, suggesting that some of the very fine pores can act as storage for metallic $\mathrm{Li}$, or that the surface storage of very active $\mathrm{C}$ is much higher than the intercalated $\mathrm{Li}$ in bulk graphite. For the samples obtained at 350 and $800{ }^{\circ} \mathrm{C}$, the reversible capacity after 50 cycles is just about 478.3 and $138.7 \mathrm{mAh} \mathrm{g}^{-1}$. The enhanced electrochemical performance of the samples obtained at $500{ }^{\circ} \mathrm{C}$ can be attributed to its unique porous structure. As compared to the carbon obtained at $350{ }^{\circ} \mathrm{C}$, higher thermaltreated temperature can offer better conductivity. However, when the temperature increase to $800{ }^{\circ} \mathrm{C}$, it will destroy its porous structure (Table 1) which is important to facilitates fast transport of electrolyte ions. Therefore, the porous carbon treated at $500{ }^{\circ} \mathrm{C}$ presents the best electrochemical performance. Furthermore, the oxygen doping and its disorder structure can give more active sites for $\mathrm{Li}^{+}$storage or adsorption, which leads to a higher reversible capacity than graphite. ${ }^{41}$ Fig. 9c shows the initial discharge-charge curves of the samples treated at 500 ${ }^{\circ} \mathrm{C}$ at different current densities. At the current density of 1000 $\mathrm{mAg}^{-1}$, a high capacity of $843.1 \mathrm{mAh} \mathrm{g}^{-1}$ can be obtained, and still can be retained at $677.9 \mathrm{mAh} \mathrm{g}^{-1}$ when the current density increasing to $5000 \mathrm{~mA} \mathrm{~g}^{-1}$. The cycling curves of the carbon materials obtained at $500{ }^{\circ} \mathrm{C}$ are shown in Fig. 9d. As shown, excellent cycle performance can be observed. At the current density of $1000 \mathrm{~mA} \mathrm{~g}^{-1}$, the discharge capacity can be retained at $289.5 \mathrm{mAh} \mathrm{g}^{-1}$ after 200 cycles. And especially, when the current density increasing to $5000 \mathrm{~mA} \mathrm{g-1} \mathrm{(13.4C,} \mathrm{according} \mathrm{to}$ the theoretical capacity of $372 \mathrm{mAh} \mathrm{g}^{-1}$ ), high discharge capacity of $216.7 \mathrm{mAh} \mathrm{g}^{-1}$ still can be obtained after 200 cycles, which is a very competitive result as compared other carbon materials, ${ }^{42-44}$ and the capacity retention can reach up to $74.9 \%$ as compared to that at the current density of $1000 \mathrm{~mA} \mathrm{~g}^{-1}$. These electrochemical tests suggest that the carbon materials obtained from recycling waste materials of lead-acid batteries are promising anodes material with high capacity and excellent rate performance.

\section{Conclusions}

Hierarchical mesoporous carbon materials were successfully produced as a side product in a novel green hydrometallurgy LABs recycling process. In this process, lead-containing parts in the spent lead acid battery paste were transferred to lead citrate precursor. Then by heat treatment and acid wash treatment, lead can be recycled from solution. Porous carbon was then collected as side-product. The resulting carbon materials have a sponge-like open porosity. High capacity and excellent rate performance was achieved when used as anode material in LIBs. Further optimization of the process and further application of the carbon materials is still in need of more research. Nevertheless, this study has already proved that hierarchical porous carbon produced from this novel hydrometallurgy LABs recycling process provides considerable potential as anode material for high-rate LIBs.

\section{Acknowledgements}

X.P. and C.D we acknowledge funding from the ERC, under grant number 259619 PHOTO EM.

\section{Notes and references}

a. Department of Materials Science and Metallurgy, University of Cambridge, 27 Charles Babbage Rd, Cambridge, UK, CB3 0FS.

Email: xh253@cam.ac.uk, rvk10@cam.ac.uk,

Tel: +44 01223331951

${ }^{b}$. School of Chemistry and Chemical Engineering, and Jiangsu Key Laboratory of Green Synthetic Chemistry for Functional Materials, Jiangsu Normal University, Xuzhou, Jiangsu 221116, P. R. China,

Email: laichao@jsnu.edu.cn

* The corresponding author

Electronic Supplementary Information (ESI) available: [details of any supplementary information available should be included here]. See DOI: $10.1039 / \mathrm{b} 000000 \mathrm{x} /$ 
$1 . \quad$ L. Chen, Z. Xu, M. Liu, Y. Huang, R. Fan, Y. Su, G. Hu, X. Peng, and X. Peng, Sci. Total Environ., 2012, 429, 191-198.

2.

M. a. Kreusch, M. J. J. S. Ponte, H. a. Ponte, N. M. S. Kaminari, C. E. B. Marino, and V. Mymrin, Resour. Conserv. Recycl., 2007, 52, 368-380.

3. M. S. Sonmez and R. V. Kumar, Hydrometallurgy, 2009, 95, 53-60.

4. J. Pan, Y. Sun, W. Li, J. Knight, and A. Manthiram, Nat. Commun., 24 2013, 4, 2178.

5.

6. L. Li, X. Zhu, D. Yang, L. Gao, J. Liu, R. V. Kumar, and J. Yang, J. Hazard. Mater., 2012, 203-204, 274-282.

7. X. Zhu, X. He, J. Yang, L. Gao, J. Liu, D. Yang, X. Sun, W. Zhang, Q. Wang, and R. V. Kumar, J. Hazard. Mater., 2013, 250-251, 387-396.

8. M. Sevilla and R. Mokaya, Energy Environ. Sci., 2014, 7, 12501280.

9. S. Dutta, A. Bhaumik, and K. C.-W. Wu, Energy Environ. Sci., 2014, 7, 3574-3592.

10. L. Ji, Z. Lin, M. Alcoutlabi, and X. Zhang, Energy Environ. Sci., $2011,4,2682-2699$

11. P. Roy and S. K. Srivastava, J. Mater. Chem. A, 2015, 3, 2454 2484 .

12. M. H. Han, E. Gonzalo, G. Singh, and T. Rojo, Energy Environ Sci., 2015, 8, 81-102.

13. J. Zhou, R. Li, X. Fan, Y. Chen, R. Han, W. Li, J. Zheng, B. Wang, and X. Li, Energy Environ. Sci., 2014, 7, 2715-2724.

14. J. Lee, J. Kim, and T. Hyeon, Adv. Mater., 2006, 18, 2073-2094.

15. Z. Ma, T. Kyotani, and A. Tomita, Chem. Commun., 2000, 23652366

16. Z. Ma, T. Kyotani, Z. Liu, O. Terasaki, and A. Tomita, Chem. Mater., 2001, 13, 4413-4415.

17. S. Che, A. E. Garcia-Bennett, X. Liu, R. P. Hodgkins, P. A. Wright, D. Zhao, O. Terasaki, and T. Tatsumi, Angew. Chemie Int. Ed., 2003, 42, 3930-3934.

18. G. Che, B. B. Lakshmi, E. R. Fisher, and C. R. Martin, Nature, 1998, 393, 346-349.

19. M. Biswal, A. Banerjee, M. Deo, and S. Ogale, Energy Environ Sci., 2013, 6, 1249-1259.

20. X. Zhu, L. Li, X. Sun, D. Yang, L. Gao, J. Liu, R. V. Kumar, and J. Yang, Hydrometallurgy, 2012, 117-118, 24-31.
21. L. Ji, Z. Lin, A. J. Medford, and X. Zhang, Carbon N. Y., 2009, 47, $3346-3354$
22.

23

25 .

26

27.

28.

29.

30

31

32.

33

34

35

36.

37.

38

39.

40
Y. S. Hu, P. Adelhelm, B. M. Smarsly, S. Hore, M. Antonietti, and J. Maier, Adv. Funct. Mater., 2007, 17, 1873-1878.

J. Yang, R. V. Kumar, and D. P. Singh, J. Chem. Technol. Biotechnol., 2012, 87, 1480-1488.

M. E. Brown, J. Chem. Soc. Faraday Trans. 1, 1973, 69, 12021212 .

P. E. Yankwich and J. L. Copeland, J. Am. Chem. Soc., 1957, 79, 2081-2086.

J. Charles, P. Kopf, and S. Toby, J. Phys. Chem., 1966, 350, 1478 1482 .

T. Gorrie, P. Kopf, and S. Toby, J. Phys. Chem., 1967, 1478, 3842 3845 .

Y. Gogotsi, A. Nikitin, H. Ye, W. Zhou, J. E. Fischer, B. Yi, H. C. Foley, and M. W. Barsoum, Nat Mater, 2003, 2, 591-594.

N. Shimodaira and a. Masui, J. Appl. Phys., 2002, 92, 902-909.

X. Xu, H. Tan, K. Xi, S. Ding, D. Yu, S. Cheng, G. Yang, X. Peng, A. Fakeeh, and R. V. Kumar, Carbon N. Y., 2015, 84, 491-499.

Y. Wang, J. Cao, Y. Zhou, J.-H. Ouyang, D. Jia, and L. Guo, J. Electrochem. Soc., 2012, 159, A579-A583.

J. Liang, Y. Jiao, M. Jaroniec, and S. Z. Qiao, Angew. Chemie Int. Ed., 2012, 51, 11496-11500.

S.-A. Wohlgemuth, R. J. White, M.-G. Willinger, M.-M. Titirici, and M. Antonietti, Green Chem., 2012, 14, 1515-1523.

K. S. W. Sing, D. H. Everett, R. a. W. Haul, L. Moscou, R. a. Pierotti, J. Rouquérol, and T. Siemieniewska, Pure Appl. Chem., $1985, \mathbf{5 7}, 603-619$

M. Kruk and M. Jaroniec, Chem. Mater., 2001, 13, 3169-3183.

L. Sun, C. Tian, M. Li, X. Meng, L. Wang, R. Wang, J. Yin, and H. Fu, J. Mater. Chem. A, 2013, 1, 6462-6470.

B. Guo, X. Wang, P. F. Fulvio, M. Chi, S. M. Mahurin, X. G. Sun, and S. Dai, Adv. Mater., 2011, 23, 4661-4666.

F. Cheng, Z. Tao, J. Liang, and J. Chen, Chem. Mater., 2008, 20, 667-681.

Z. Yang, Y. Xia, and R. Mokaya, J. Am. Chem. Soc., 2007, 129, $1673-1679$.

S. Goriparti, E. Miele, F. De Angelis, E. Di Fabrizio, R. Proietti Zaccaria, and C. Capiglia, J. Power Sources, 2014, 257, 421-443. 
41. J. Hou, C. Cao, F. Idrees, and X. Ma, ACS Nano, 2015, 9, 2556

2564.

42. J. Ming, Y. Wu, G. Liang, J.-B. Park, F. Zhao, and Y.-K. Sun,

Green Chem., 2013, 15, 2722-2726.

43. D.-C. Guo, F. Han, and A.-H. Lu, Chem. - A Eur. J., 2015, 21, $1520-1525$.

44. V. Etacheri, C. Wang, M. J. O'Connell, C. K. Chan, and V. G. Pol, J. Mater. Chem. A, 2015, 3, 9861-9868. 